\title{
The Osgood-Schlatter's syndrome and involvement of children of young age in sports
}

Amela Halilbašić1,2*, Amir Kreso, Muhamed Klepić1, Amila Jaganjac², Dijana Avdić

${ }^{1}$ Public Center for Sports Medicine of Canton Sarajevo, Sarajevo, Bosnia and Herzegovina, '2Department of physiotherapy, Faculty of Health Studies, University of Sarajevo, Sarajevo, Bosnia and Herzegovina

\begin{abstract}
Introduction: In recent years, the practice of young children training to master sports has become a trend. Said exposes young children who are training intensively to various external risk factors such as social isolation, addiction, frequent injuries, and syndrome of overload. Enablers of this behavior are commonly parents and coaches who notice the child's abilities stand out from those of other children in the group and find that such talent requires intensive sport-specific training. The purpose of this study was to determine the average age of the patients and the average age when the first symptoms of the disease appeared as well as to provide an analysis of the average duration of children being actively involved in sports activities before the first symptoms of OSD appeared.
\end{abstract}

Methods: The research has been conducted on 200 patients who were previously diagnosed with OsgoodSchlatter's syndrome. The participants were divided into two groups each containing 100 patients, first group -aerobic sports (football and basketball) and the second group -anaerobic sports (karate and taekwondo). Personal information, anthropometric measurements, complete medical, and sports history were taken from the patients. A clinical examination was conducted by the researcher himself. The study was prospective, clinical, comparative, analytical, and descriptive. The research was conducted in Public Center for Sports Medicine of Canton Sarajevo.

Results: The average age when the patients started with intensive training was highest with basketball players (7.8 years) following with karate trainees (6.8 years). Basketball players had statistically the lowest duration of being actively involved in sports activities before the first symptoms of OSD appeared (5.4 years). No statistically significant difference in the average duration of training was discovered between the test groups. The average age when knee pain or swelling under the knee first appeared was at the age of 11.4 years with players of aerobic sports and 11.8 years with players of anaerobic sports. Furthermore, no statistically significant difference was found between test groups and subgroups. Before the first appearance of knee pain, the taekwondo patients had been in training the longest ( 4.7 years) and basketball players the least amount of time

*Corresponding author: Amela Halilbašić, Public Centre for Sports Medicine of Canton Sarajevo, Patriotske Lige36, Sarajevo, Bosnia and Herzegovina. Tel: +38761503125.

E-mail: amela.halilbasic@gmail.com

Submitted: 18 May 2019/Accepted: 25 July 2019

DOI: https://doi.ora/10.17532/ihsci.2019.894 (3.4 years).

Conclusion: By conducting retrospective analysis, it has been concluded that children had started training at the age of 3 or 4 years and had encountered the first symptoms of OSD at the ages of 4 years (football) and 6 years (taekwondo). Research 
showed that the early involvement of children in sports and their early specialization in sports are both external risk factors that have a dominant influence on OSD development.

Key words: Osgood-Schlatter disease; growth-zone; early sport-specialization

\section{INTRODUCTION}

Medical research shows that $25-40 \%$ of children and adolescents complain of chronic knee pain during their growth and development years. The presence of pain limits their sports activities and is later often diagnosed as Osgood Schlatter's syndrome $(\mathrm{OSD})(1,2)$. The skeletal system of children who are actively involved in sports activities is prone to specific injuries, apophysitis, and osteochondrosis. Osgood-Schlatter'ssyndrome is the most common juvenile osteochondrosis. (3) Two findings can be highlighted from recent medical research, first young children are involved in organized sports activities more frequently than ever, and second the first symptoms of OSD have been reported in children at the age of 5.5 years (4). Enablers of this behavior are commonly parents themselves who believe that introducing sports activities at an early age creates positive living habits and improves the health of the child. The aforementioned presents a strong risk factor for the development of OSD because both internal (early age) and external (sports activities) risk factors are combined (5-7). It is important to highlight that the motor skills complex needed for certain sports is not yet developed in children until after puberty (5). Due to early involvement in sports, children in their early adolescence have already been actively doing sports for several years. The latest research has shown that children from age 10 to 12 years have already been actively involved in sports activities for 5 to 7 years (4). An increasing number of parents and coaches believe that the best way to master a sport and become a winner is dedicating to one sports activity throughout the year as well as involving children in sports at an early age. Limiting and focusing the child on a certain sport to increase the chances of being elected into an elite team is not considered the most ideal way to achieve top results (6-8). In recent years, the practice of specialization on a certain type of sports activity at an early age can be encountered. This exposes children to numerous external risk factors such as social isolation, excessive addiction, frequent injuries, overtraining, and syndrome of overload. In practice, during the training process, trainers notice that one child's abilities stand out from those of other children in the group and find that such talent requires intensive sport-specific training $(6,7,9)$. During the training process, the specifics of the child's growth and development are not taken into account, which leads to exceeding the endurance limits of the child's organism. Sport specialization is defined as intense training of a certain type of sport during the whole year and excludes other sports. This kind of training can increase the risk of injuries, lead to psychological stress, and overload in early life. There are physical and physiological differences between children and adults which are precisely the reason for the increased sensitivity of children to injuries. Children often train with several sports clubs at the same time or they play different sports which means their activities are not limited to a particular season $(9,10)$. Results of various studies indicate that limiting children to only one form of sporting activity is not the most efficient way to acquire elite status in said sport $(6,7)$. The aim of this study was to determine the average age of the patients and the average age when the first symptoms of the disease appeared as well as to provide an analysis of average exposure of children to active training before the first symptoms of OSD appeared.

\section{METHODS}

The research was conducted on 200 patients with knee impairments who were clinically diagnosed with Osgood-Schlatter'ssyndrome. Depending on the type of sport they were practicing, the participants were divided into two groups, each containing 100 patients, the first group -aerobic sports (football and basketball) and the second group -anaerobic sports (karate and taekwondo). All patients were clinically evaluated using the same subjective and objective criteria. Personal data and anthropometric measurements (Body weight, body height) were taken from the patients, and body 
mass index was calculated. A detailed medical and sports history was taken for each patient to perform a cross-section and summation of the external risk factors that led to the appearance of OsgoodSchlatter's syndrome. The clinical examination of both knees on all patients was conducted by the researcher himself. Subjective criteria referred to information on the presence of pain in the frontal part of the knee concerning the training process. The study was prospective, clinical, comparative, analytical, and descriptive. The research was conducted in Public Center for Sports Medicine of Canton Sarajevo. For research purposes, medical records of examinees, sportsmen were used. Software used for statistical data analysis was SPSS for Windows (version 20.0, SPSS Inc., Chicago, Illinois, USA) and Microsoft Excel (version 13 of Microsoft Corporation, Redmond, WA, USA).

\section{RESULTS}

The results of the ANOVA test have shown that the average age of patients training karate was statistically significantly lower than the average age of patients belonging to other subgroups, $\mathrm{F}=3.511$; $p=0.016$. In the examined subgroups, the oldest was basketball players (13.38 \pm 1.36 years), followed by taekwondo trainees $(13.30 \pm 1.71$ years $)$. The lowest average age was recorded in the case of karate trainees $(12.40 \pm 1.71$ years $)$, followed by football players $(12.96 \pm 1.88$ years $)$. The average age of patients in the aerobic sports group was $13.17 \pm 1.65$ years and in the anaerobic group, it was $12.85 \pm 1.76 y$ years. No statistically significant difference in the average age of patients in aerobic and anaerobic sports was determined, $\mathrm{F}=1.751$; $p=0.187$ (Table 1).

The results of the ANOVA test have shown that the average age at which patients began actively training were statistically significantly increased in the case of basketball players compared to the average age of patients belonging to other subgroups, $\mathrm{F}=3.958$; $p=0.009$. In the examined subgroups, the average age at which patients began to train was the highest in basketball players $7.80 \pm 2.25$ years, followed by karate trainees with $6.82 \pm 1.79$ years. The average age for football players was $6.72 \pm x 1.64$ years and for taekwondo, trainees were $6.72 \pm 1.71$ years.
TABLE 1. The average age of patients

\begin{tabular}{lcccccc}
\hline Sport & $n$ & $\mathrm{X}$ & $\mathrm{SD}$ & $\mathrm{SEM}$ & Minimum & Maximum \\
\hline Football & 50 & 12.96 & 1.88 & 0.26 & 5.00 & 15.00 \\
Basketball & 50 & 13.38 & 1.36 & 0.19 & 11.00 & 16.00 \\
Karate & 50 & 12.40 & 1.71 & 0.24 & 8.00 & 15.00 \\
Taekwondo & 50 & 13.30 & 1.71 & 0.24 & 6.00 & 15.00 \\
$\mathrm{~F}=3.511 ; p=0.016$ & & & & & \\
$\begin{array}{l}\text { Aerobic } \\
\text { sports }\end{array}$ & 100 & 13.17 & 1.65 & 0.16 & 5.00 & 16.00 \\
$\begin{array}{l}\text { Anaerobic } \\
\text { sports }\end{array}$ & 100 & 12.85 & 1.76 & 0.17 & 6.00 & 15.00 \\
F=1.751; $p=0.187$ & & & & & \\
\hline
\end{tabular}

SEM: Standard error of mean, SD: Standard deviation

There is no statistically significant difference in the average age at which patients started active training in aerobic and anaerobic sports was determined, $\mathrm{F}=3.334 ; p=0.069$ (Table 2).

In the examined subgroups, the average exposure to training was the longest in TWD trainees $6.66 \pm$ 2.20 years, followed by football players with $6.32 \pm$ 1.93 years. In the case of karatists, the average duration was $5.94 \pm 1.97$ years. The average duration of training was significantly lower $(5.40 \pm 2.19$ years $)$ in the case of basketball players compared to patients from other subgroups, $\mathrm{F}=3.371 ; p=0.020$. There is no statistically significant difference in the average durations determined in aerobic and anaerobic sports, $\mathrm{F}=2.171 ; p=0.142$ (Table 3).

The average age in which knee pain or swelling first appeared among the patients in the aerobic sports group was $11.43 \pm 1.84$ years and in the anaerobic sports group, it was $11.82 \pm 2.26$ years. The results of the ANOVA test have shown that no statistically significant difference was found in the examined groups $(p=0.680)$. There was no statistically significant difference in the subgroups compared to the investigated sports $(p=0.821)$ (Table 4).

The results of the ANOVA test have shown that the average training duration before the appearance of knee impairments was the longest in the case of TWD trainees $(4.70 \pm 2.18$ years $)$ and the shortest in the case of basketball players $(3.42 \pm$ 2.28 years $),(p=0.007)$. There was no statistically significant difference between the examined groups $(p=0.235)$ (Table 5). 
TABLE 2. The average age of patients at the beginning of active training

\begin{tabular}{lcccccc}
\hline Sport & $n$ & $\mathrm{X}$ (years) & SD & SEM & Minimum & Maximum \\
\hline Football & 50 & 6.72 & 1.64 & 0.23 & 3.00 & 12.00 \\
Basketball & 50 & 7.80 & 2.25 & 0.31 & 4.00 & 13.00 \\
Karate & 50 & 6.82 & 1.79 & 0.25 & 4.00 & 11.00 \\
Taekwondo & 50 & 6.72 & 1.71 & 0.24 & 4.00 & 10.00 \\
F=3.958; $p=0.009$ & & & & & & \\
Aerobic sports & 100 & 7.26 & 2.03 & 0.20 & 4.00 & 13.00 \\
Anaerobic sports & 100 & 6.77 & 1.74 & 0.17 & 4.00 & 11.00 \\
F=3.334; $p=0.069$ & & & & & & \\
\hline
\end{tabular}

SEM: Standard error of mean, SD: Standard deviation

TABLE 3. The average duration of active training

\begin{tabular}{lcccccc}
\hline Sport & $n$ & $\mathrm{X}$ (years) & SD & SEM & Minimum & Maximum \\
\hline Football & 50 & 6.32 & 1.93 & 0.27 & 2.00 & 10.00 \\
Basketball & 50 & 5.40 & 2.19 & 0.31 & 2.00 & 9.00 \\
Karate & 50 & 5.94 & 1.97 & 0.27 & 2.00 & 9.00 \\
Taekwondo & 50 & 6.66 & 2.20 & 0.31 & 1.00 & 10.00 \\
F=3.371; $p=0.020$ & & & & & & \\
Aerobic sports & 100 & 5.86 & 2.10 & 0.21 & 2.00 & 10.00 \\
Anaerobic sports & 100 & 6.30 & 2.11 & 0.21 & 1.00 & 10.00 \\
$\mathrm{~F}=2.171 ; p=0.142$ & & & & & & \\
\hline
\end{tabular}

SEM: Standard error of mean, SD: Standard deviation

TABLE 4. The average age of patients at which knee pain or swelling first appeared

\begin{tabular}{lcccccc}
\hline Sport & $n$ & $\mathrm{X}$ & $\mathrm{SD}$ & $\mathrm{SEM}$ & Minimum & Maximum \\
\hline Football & 50 & 11.28 & 1.91 & 0.27 & 4.00 & 14.00 \\
Basketball & 50 & 11.58 & 1.77 & 0.25 & 7.00 & 15.00 \\
Karate & 50 & 12.38 & 3.03 & 1.84 & 8.00 & 12.00 \\
Taekwondo & 50 & 11.26 & 1.66 & 0.23 & 6.00 & 14.00 \\
$\mathrm{~F}=0.306 ; p=0.821$ & & & & & & \\
Aerobic sports & 100 & 11.43 & 1.84 & 0.18 & 4.00 & 15.00 \\
Anaerobic sports & 100 & 11.82 & 2.26 & 0.92 & 6.00 & 12.00 \\
$\mathrm{~F}=0.170 ; p=0.680$ & & & & & & \\
\hline
\end{tabular}

SEM: Standard error of mean, SD: Standard deviation

TABLE 5. Average training duration when knee pain or swelling first appeared

\begin{tabular}{lcccccc}
\hline Sport & $n$ & $\mathrm{X}$ & $\mathrm{SD}$ & SEM & Minimum & Maximum \\
\hline Football & 50 & 4.41 & 1.85 & 0.26 & 1.00 & 8.00 \\
Basketball & 50 & 3.42 & 2.28 & 0.32 & 00 & 9.00 \\
Karate & 50 & 3.82 & 1.61 & 0.22 & 1.00 & 7.00 \\
Taekwondo & 50 & 4.70 & 2.18 & 0.30 & 1.00 & 9.00 \\
F=4.141; $p=0.007$ & & & & & & \\
Aerobic sports & 100 & 3.91 & 2.12 & 0.21 & 00 & 9.00 \\
Anaerobic sports & 100 & 4.26 & 1.96 & 0.19 & 1.00 & 9.00 \\
F=1.420; $p=0.235$ & & & & & & \\
\hline
\end{tabular}

SEM: Standard error of mean, SD: Standard deviation 


\section{DISCUSSION}

By conducting a retrospective analysis of the age at which the patients started training actively, it was discovered that there were children who started training football even at the age of 3 years. In comparison, the lowest age present in other analyzed sports was 4 years. After analyzing the history of the disease, it was concluded that children experienced the first symptoms of OSD at 4 years (football) and 6 years (taekwondo). In aerobic sports, the minimum was 4 years and in anaerobic sports, it was 6 years. Also, the research showed that the first symptoms of OSD occurred after a minimum of 1 year of continuous sports activity. Although the analysis of said parameters showed no statistically significant differences in the groups and subgroups which were examined, the study concluded that early inclusion of children in sports and early sports specialization are external risk factors that have a dominant influence on OSD development. DiFiori et al. have pointed out that risk factors of the youngest population, 6-12 years of age, are currently not very known, and the rate of injuries in this young population is very low $(9,11,12)$ Recent research shows that in the last decade, children are significantly more involved in organized sports activities. Halilbašic et al. have concluded that the first OSD symptoms have occurred in children over the age of 5.5 years (4). Malina, Mostafavifar et al. believe that the risks caused by early sports specialization are on the rise. In the last couple of years, sports academies are being opened in our country to enable the early inclusion of children in recreational sports. They are led by trained coaches with the necessary qualifications. During the week, children practice various forms of sports: Athletics, swimming, football, volleyball, or basketball. In the future opening, sports academies should be encouraged to reduce the chances of children being involved in individual sports, causing them to focus solely on winning rather than on the overall development of the child.

\section{CONCLUSION}

By conducting retrospective analysis, it has been concluded that children had started training at the age of 3 or 4 years and had encountered the first symptoms of OSD at the ages of 4 years (football) and 6 years (taekwondo). Research showed that the early involvement of children in sports and their early specialization in sports are both external risk factors that have a dominant influence on OSD development.

\section{REFERENCES}

1. Domingues M.Osgood-Schlatter's syndrome and functional impairment of the knee in young football players.Br J Sports Med2013;47(10):e3. https://doi.org/10.1136/bjsports-2013-092558.88.

2. Nakase J, Aiba T, Goshima K, Takahashi R, Toratani T, Kosaka M, et al Relationship between the skeletal maturation of the distal attachment of the patellar tendon and physical features in preadolescent male football players. Knee Surg Sports TraumatolArthrosc2014;22:195-9.

https://doi.org/10.1007/s00167-012-2353-3.

3. Gillespie H. Osteochondroses and apophyseal injuries of the foot in the young athlete.Curr Sports Med Rep2010;9(5):265-8.

https://doi.org/10.1249/jsr.0b013e3181f19488.

4. Halilbašić A, Avdić D, Kreso A, Begović B, Jaganjac A, Marić M. Importance of clinical examination in diagnostics of Osgood-Schlatter disease in boys playing soccer or basketball. J Health Sci2012;2(1):21-8.

https://doi.org/10.17532/jhsci.2012.59.

5. Adirim TA, Barouh A. Common orthopedic injuries in young athletes. CurrPaediatr2006;16(3):205-10.

6. Malina RM. Early sport specialization: roots, effectiveness, risks. Curr Sports Med Rep2010;9(6):364-71.

https://doi.org/10.1249/jsr.0b013e3181fe3166.

7. Mostafavifar AM, Best TM, Myer GD. Early sport specialisation, does it lead to long-term problems? Br J Sports Med2013;47(17):1060-1.

https://doi.org/10.1136/bjsports-2012-092005.

8. Theisen D, Frisch A, Malisoux L, Urhausen A, Croisier JL, Seil R. Injury risk is different in team and individual youth sport. J Sci Med Sport2013;16(3):200-4.

https://doi.org/10.1016/j.jsams.2012.07.007.

9. DiFiori JP, Benjamin HJ, Brenner J, Gregory A, Jayanthi N, Landry GL, et al. Overuse injuries and burnout in youth sports: A position statement from the American Medical Society for Sports Medicine. Clin J Sport Med2014;24(1):3-20.

https://doi.org/10.1097/jsm.0000000000000060.

10. Jayanthi N, Pinkham C, Dugas L, Patrick B, Labella C. Sports specialization in young athletes: Evidence-based recommendations. Sports Health2013;5(3):251-7.

https://doi.org/10.1177/1941738112464626.

11. Froholdt $A$, Olsen $O E$, Bahr R. Low risk of injuries among children playing organized soccer: A prospective cohort study.Am J Sports Med2009;37:1155-60.

https://doi.org/10.1177/0363546508330132.

12. Hanada M, Koyama H, Takahashi M, Matsuyama Y. Relationship between the clinical findings and radiographic severity in Osgood-Schlatter disease. Open Access J Sports Med2012;3:17-20.

https://doi.org/10.2147/oajsm.s29115. 